\title{
DIANA HITZKE
}

0000-0003-0773-0201

Justus-Liebig-Universität Gießen

Fachbereich 05 - Sprache, Literatur, Kultur

Institut für Slavistik

35394 Gießen

Otto-Behaghel-Str. 10D

diana.hitzke@slavistik.uni-giessen.de

\section{ПИСАТЕЛЬ-ПЕРЕВОДЧИК. МНОГОЯЗЫЧНОСТЬ ОЛЬГИ МАРТЫНОВОЙ}

\author{
THE AUTHOR AS TRANSLATOR. \\ OLGA MARTYNOVA`S MULTILINGUALISM
}

Ольга Мартынова пишет на двух языках: стихи на русском и прозу на немецком языке. Для написания стихов, как говорит автор, необходима большая скорость, которая возможна для нее только на русском языке. Несмотря на это, она переводит свои русские стихи (вместе с Эльке Эрб) на немецкий язык. В переводе стихотворения Римские стихи (3), например, русским рифмам «инеем - именем - выменем» в немецкой версии соответствуют, с одной стороны, буквальные переводы (Raureif - Name - Euter), а с другой стороны - «визуально» зарифмованные слова «Namen - Kolonnaden - oben». В своей статье я хочу показать, как Ольга Мартынова следует поэтике перевода. Она не боится, что в переводе она покажется «плоской поэтессой» (как сказал Флобер о переводе Тургеневым Пушкина: он плоский, ваш поэт [«Il est plat, votre poète»]). Она пишет связанные друг с другом книги: стихи на русском языке и прозу на немецком. Наряду с этими двумя языками, язык птиц также играет определенную роль в ее творчестве. В категоризации различных типов писателей - от мастера пера к графоману - Ольгу Мартынову можно отнести к типу писателя-переводчика.

Ключевые слова: Ольга Мартынова, поэтика перевода, многоязычность, транскультурность.

Olga Martynova writes in two languages: poetry in Russian and prose in German. Writing poetry, as Martynova states, requires very quick thinking, which is only possible for her in the Russian language. In spite of this limitation, she translates her Russian verses into German - in collaboration with Elke Erb. To consider an example, in "Verse von Rom (3)", the Russian rhymes "инеем - именем - выменем" are rendered on the one hand literally, as "Raureif - Name - Euter", and on the other as "visual rhymes': "Namen - Kolonnaden - oben". The paper aims to show how Martynova practises a poetics of translation. She is not afraid of coming across as a "flat" poet in translation (as for example Flaubert said about Pushkin in Turgenev's renditions: "Il est plat, votre 
poète"). Instead, she writes books in German and Russian, books which are linked to each other. Another language important for her works is the language of birds. The paper analyses in what sense Martynova can be viewed as an author-translator (within a broader typology of writers).

Keywords: Olga Martynova, poetics of translation, multilingualism, cross-cultural relations.

Ольга Мартынова пишет на двух языках: стихи на русском и прозу на немецком языке. В этом можно сравнить ее с другими многоязычными авторами, такими, например, как Джозеф Конрад или Владимир Набоков ${ }^{1}$. При этом, в отличие от многих других подобных авторов, Мартынова не сменила язык - она продолжает писать на обоих языках. В Германии и в немецкоязычных странах она зарекомендовала себя как писатель «восточного поворота» ${ }^{2}$ немецкой литературы, но ее творчество развивается и вне рамок этой атрибуции. «Восточный поворот» описывает Бриджид Хейнс:

It is certainly possible to identify a wave of writers from former Eastern-bloc countries who have settled in one of the German-speaking countries since the fall of communism and are writing in German [...]. [T] he undeniable impact of these writers may also be noted in their receipt of mainstream prizes, such as the Swiss Book Prize (awarded to Melinda Nadj Abonji and Catalin Dorian Florescu in 2010 and 2011 respectively), the German Book Prize (awarded to Ilma Rakusa, Abonji and Terézia Mora in 2009, 2010 and 2013 respectively), the Leipzig Book Fair Prize (awarded to Saša Stanišič in 2014, and previously to Mora, Ilija Trojanow and Sybille Lewitscharoff), and the Festival of German-Language Literature, formerly the Ingeborg Bachmann Prize (awarded to Olga Martynowa and Katja Petrowskaja in 2012 and 2013 respectively) ${ }^{3}$.

Другой контекст, в котором можно рассмотреть ее творчество, связан с переводами. Как в современной русской, так и в немецкоязычной литературе существует целый ряд героев-протагонистов, которые работают (или действуют) переводчиками, как, например, в книгах Михаила Шишкина (Beнерин волос, 2005) ${ }^{4}$, Людмилы Улицкой (Даниэль Штайн, переводчик, 2006) Ольги Грязновой (Der Russe ist einer, der Birken liebt, 2012) ${ }^{6}$, Ирены Брежной (Die undankbare Fremde, 2012) 7 и Маши Дабич (Reibungsverluste, 2017) . $^{8}$

\footnotetext{
${ }^{1}$ На тему «литература и многоязычность» ср.: G. Radaelli, Literarische Mehrsprachigkeit. Sprachwechsel bei Elias Canetti und Ingeborg Bachmann, Berlin: Akademie Verlag 2011.

${ }^{2}$ B. Haines, Introduction. The Eastern European Turn in Contemporary German-Language Literature, «German Life and Letters» 2015, № 68/2.

${ }^{3}$ Там же, с. $145-146$.

${ }^{4}$ М. П. Шишкин, Венерин волос, Москва: Вагриус 2005.

5 Л. Е. Улицкая, Даниэль Штайн, переводчик, Москва: Эксмо 2006.

${ }^{6}$ O. Grjasnowa, Der Russe ist einer, der Birken liebt, München: Hanser 2012.

${ }^{7}$ I. Brežná, Die undankbare Fremde, Berlin: Galiani 2012.

${ }^{8}$ M. Dabić, Reibungsverluste, Wien: Edition Atelier 2017.
} 


\section{Писатель-переводчик}

На вопрос, почему она пишет стихи на русском языке, а прозу на немецком, Мартынова отвечает: «Ну, потому что мне это нравится. Характеристики языков не имеют к этому никакого отношения» ${ }^{9}$. В другом месте, в эпилоге немецкого перевода стихов Von Tschwirik und Tschwirka, она объясняет, что для написания стихов, необходима большая скорость, которая возможна для нее только на русском языке ${ }^{10}$.

Вместе с тем она сама переводит свои русские стихи - совместно с переводчицей Эльке Эрб - на немецкий язык. Ольга Мартынова следует поэтике перевода и не боится, что в переводе она покажется «плоской поэтессой» (как сказал Флобер о переводе Тургеневым Пушкина: «он плоский, ваш поэт» [«Il est plat, votre poète»]) $)^{11}$, она пишет связанные друг с другом книги: стихи на русском языке и прозу на немецком. Помимо этих двух языков, «язык» птиц также играет определенную роль в ее творчестве. В категоризации различных типов писателей - от мастера пера к графоману - Ольгу Мартынову можно отнести к типу писателя-переводчика.

Она действует как посредник между языками и культурами, например, в связанных друг с другом книгах Sogar Papageien überleben uns (2010, Hac даже попугаи переживут $)^{12}$ и О Введенском. О Чвирике и Чвирке. Исследования в стихах (2010) ${ }^{13}$. В книге стихов о Введенском искусство связано с исследованиями. Так в предисловии к русскому изданию стихотворений Виктор Бейлис пишет:

Из того немногого, что до сих пор говорилось о Введенском, все написано на философском или же филологическом наречии; Ольга Мартынова впервые взялась трактовать эту тему в стихах, и мне представляется ее подход существенным и продуктивным. Все труды, посвященные Введенскому, начинаются так или иначе со слов «звезда бессмыслицы», с упоминания о том, что этот автор предвосхитил на тридцать лет литературу абсурда и т. $\Pi^{14}$.

${ }^{9}$ O. Мартынова, Dichter im Porträt. Olga Martynova, [электронный ресурс] https://www. youtube.com/watch? $\mathrm{v}=\mathrm{hr} 4 \mathrm{H}-\mathrm{VOuULE} \&$ feature=youtu.be [29.09.2018].

${ }^{10}$ O. Martynova, Von Tschwirik und Tschwirka. Gedichte, Graz, Wien: Droschl 2012, c. 90.

${ }^{11}$ «When the quatralingual Ivan Turgenev, living in Paris in the 1870 s, presented some poems by Pushkin in his own French translation to Gustave Flaubert, the latter shrugged: 'Il est plat, votre poète' [He`s flat, your poet]». C. Emerson, The Cambridge Introduction to Russian Literature, Cambridge и др.: Cambridge University Press 2008, с. 4.

${ }^{12}$ O. Martynova, Sogar Papageien überleben uns, München: btb 2012.

${ }^{13}$ О. Мартынова, О Введенском. О Чвирике и Чвирке. Исследования в стихах, Серия «Русский Гулливер», Москва: Центр современной литературы 2010. c. $9-10$.

${ }^{14}$ В. Бейлис, Предисловие, [в:] О. Мартынова, О Введенском. О Чвирике и Чвирке..., 
В книге Sogar Papageien überleben uns в восьмидесяти восьми коротких фрагментах, каждый из которых от трех до пяти страниц, главная героиня Марина размышляет о своем прошлом в Санкт-Петербурге, думает о друзьях и близких и об отношениях с Андреасом, которого она встретила 20 лет назад, когда он приезжал студентом в Петербург (тогда Ленинград). Спустя много времени, приехав в Германию с лекционным туром о русских поэтах Хармсе и Введенском, она снова встречает Андреаса. Сейчас он профессор немецкой литературы. Тогда, 20 лет назад вместо того, чтобы жениться на Марине, вернувшись в Германию, он женился на Сабине. Несмотря на это, Марина и Андреас все это время остались в контакте. Когда сначала Марина, а затем Андреас развелись со своими партнерами, они начали думать об углублении своих отношений, а теперь Андреас даже мечтает о свадьбе.

В рассказе автор все время отсылает читателя к разным местам и временам. Весь текст структурирован по времени и каждый отрывок текста начинается с временной шкалы, расположенной сразу под его заглавием. На этой временной шкале выделяются годы, которые упоминаются и обсуждаются в конкретном отрывке.

\section{Транскультурные ссылки - о Риме, Италии и Рафаэле}

В книге много транскультурных ссылок, как в описании отношений Марины с Андреасом из Западной Германии, а также с ее друзьями из Америки и Франции, так и на дискурсивном и литературно-интертекстуальном уровнях.

Итак, в отрывке под названием «Оригиналы и копии» Марина думает о следующем:

Wie hätten die Westeuropäer gelebt, zu was wären sie geworden, hätten die Türken zu der Zeit, als Italiens Boden auf der Suche nach antiken Plastiken durchgewühlt wurde, nicht Konstantinopel, sondern Rom erobert? [...] Sie, die Westeuropäer hätten dann keine Antike, weder Laokoon noch Raffaels Loggien, sie hätten dann mit der byzantinischen Kunst vorliebnehmen müssen, die sie bei uns hätten einholen und kopieren müssen ${ }^{15}$.

Как бы жили западные европейцы, кем бы они стали, если бы турки завоевали не Константинополь, а Рим, в то время, когда велись поиски древних скульптур в землях Италии? [...] У них, у западноевропейцев, не было бы античности, ни Лаокоона, ни Лоджии Рафаэля, им тогда пришлось бы довольствоваться византийским искусством, которое им нужно было бы нагнать и скопировать у нас ${ }^{16}$.

\footnotetext{
${ }^{15}$ O. Martynova, Sogar Papageien..., c. 162.

${ }^{16}$ Переведено автором статьи - Д. Х.
} 
Эта цитата связана с другими текстовыми отрывками о Риме, Италии и Рафаэле и с соответствующим межтекстуальными ссылками. Например, Андреас и Марина с другом Николаем посещают кафе «Грекко» в Риме, и они там сидят под портретом Николая Гоголя:

Der arme Andreas; es wäre doch äußerst unhöflich gewesen, die Einladung abzulehnen. Wir suchten uns im Caffè Greco den Tisch aus, über dem Nikolaj Gogols zartes Gesicht, einem rotwangigen ukrainischen Mädel mit Schnurrbärtchen ähnelnd, von der Wand herablächelte ${ }^{17}$.

Бедный Андреас; было бы крайне невежливо, отказаться от приглашения. Мы выбрали в Caffè Greco стол, над которым улыбалось со стены тонкое лицо Николая Гоголя, напоминающее краснощёкую украинскую девушку с усиками ${ }^{18}$.

Рассказ Гоголя Портрет здесь не упоминается, даже слово «портрет» не используется в описании сцены, но для знатоков русской литературы намек очевиден, как и само кафе «Грекко», известное как место встречи русских художников в Риме. Гоголь был тесно связан с Римом, где он неоднократно побывал с 1837-го по 1842 год. В отрывке Рuм он описывает город. Рассказ Портрет содержит целый ряд точек соприкосновения с Рафаэлем и Римом, с одной стороны, ${ }^{19}$ и византийским искусством - с другой ${ }^{20}$.

Naturally, Gogol's appreciation of Raphael became much deeper and more concrete while he was in Rome. He wrote to N. Ya. Prokopovich that only in Rome could one find out the real nature of Raphael [...]. He delighted in showing friends around Rome's art treasures, and his itinerary for Smirnova's visit exhaustively covers Raphael's works not only as a painter but also as an architect. [...] Therefore one is not surprised to discover that art is treated in a more abstract way in the first edition of Portret ('The Portrait', 1834), which includes a parallel with Raphael's 'vision': the Virgin appears to the artist in a dream while he is toiling in spiritual anguish to paint her image. The 1842 edition of Portret, on the other hand, discusses in much more depth the essence of morally inspiring art and how it can be realized. Raphael's name is encountered only in that version, and is repeated a number of $\operatorname{times}^{21}$.

Интертекстуальной ссылкой на Портрет Мартынова обращает внимание на византийское искусство и различное понимание оригинала и оригинальности:

\footnotetext{
${ }^{17}$ O. Martynova, Sogar Papageien..., c. 161.

${ }^{18}$ Переведено автором статьи - Д. Х.

${ }^{19}$ Cp.: I. Pearson, Raphael as Seen by Russian Writers from Zhukovsky to Turgenev, «The Slavonic and East European Review» 1981, № 59/3, c. 354-358.

${ }^{20}$ Cp.: M. P. Ginsburg, Portrait Stories, New York: Fordham University Press 2015.

${ }^{21}$ I. Pearson, Raphael as Seen..., c. 355.
} 
There are, then, two different stories told in 〈The Portrait〉. The first is the story of Chartkov, and it tells of the destruction of art by money; it is centered around the opposition between original and copy. The second is the story of the portrait painted by the old painter, and it shows art as analogous to money; it centers around the notion of representation as adequation (or lack thereof). [...] In the diagnosis offered by the story, then, the root problem would be not the loss of originality but the introduction of originality as a criterion for the production and evaluation of images. What would characterize the «decline〉 of art (and of the portrait), then, what has been lost, would be the power of the image or the valorization of and attention to this power ${ }^{22}$.

Обращением к образам Рима, Рафаэля и Италии Мартынова намекает на долгие традиции связей между Римом и Россией. Вследствие этого транскультуральность в ее творчестве не кажется просто феноменом настоящего времени. Книга стихов Ольги Мартыновой и Елены Шварц под названием Rom liegt irgendwo in Russland: Zwei russische Dichterinnen im lyrischen Dialog ӥbеr Rom (Рим находится где-то в России: две русские поэтессы в лирическом диалоге о Риме $)^{23}$ следует традиции межкультурной связи между Россией и Римом. В этих стихах Мартынова и Шварц ссылаются на Римские элегии Бродского, которые также напоминают римские элегии Гете, написанные им в период с 1788-го по 1790-й год. В послесловии к своим стихам Мартынова пишет о переводе стихотворений и о взаимосвязи немецкого и русского языков. Она дает также конкретные примеры в тексте. В переводе стихотворения Римские стихи (3)24, например, русским рифмам «инеем - именем - выменем» в немецкой версии соответствуют, с одной стороны, буквальные переводы (Raureif - Name - Euter) и, с другой стороны, «визуально» зарифмованные слова «Namen - Kolonnaden - oben» ${ }^{25}$.

\section{Римские стихи (3)}

Пусть припозднившаяся осень

Расслоилась как слюда,

Пусть прибеднившийся ноябрь каштаны прячет по карманам,

Но ночью принесли неведомые духи

Душистых римских шишек - от щедрых римских сосен.

Мужайся осень, не беда,

Что съеден край твоих беззубых десен

${ }^{22}$ M. P. Ginsburg, Portrait Stories ..., c. 155.

${ }^{23}$ O. Martynova, J. Schwarz, Rom liegt irgendwo in Russland. Zwei russische Dichterinnen im lyrischen Dialog über Rom. Gedichte Russisch / Deutsch, пер. E. Erb, O. Martynova, Wien, Lana: Edition per procura 2006.

${ }^{24}$ O. Martynova, Von Tschwirik und Tschwirka..., c. 88.

${ }^{25}$ Там же, с. 89-93. 
Лимонным инеем,

Что темный день ни полюбить, ни разлюбить не можешь

И говоришь: «Заткнись, мое дурное сердце»,

И темный день назвать его не можешь именем,

Что плачет сад, как иволга сине-желтый,

Что перегружена земля, что пусто небо

(В нем только киснет воздух волглый),

Что страшный мрамор римских колонад

Торчит из-под земли, как будто кто

Зарыл корову кверху выменем -

Зимой приехать в Рим,

Как сердце утопить в молчаньи (в журчаньи) девственной воды,

Как солнце вырыть из-под снега ${ }^{26}$.

Verse von Rom (3)

Wenn auch der etwas verspätete Herbst

sich aufblätterte wie Glimmer

und der sich arm stellende November die Kastanien in den Taschen versteckt,

brachten unbekannte Geister aber doch über Nacht

duftende römische Zapfen - von den freigebigen römischen Pinien.

Ermanne dich, Herbst, es ist kein Unglück,

daß den Rand deines zahnlosen Zahnfleischs

Zitronen-Rauhreif beizt,

daß du den dunklen Tag nicht lieben kannst und auch nicht nicht mehr lieben,

und du sagst: "Halt dich still, dummes Herz",

und du den dunklen Tag nicht nennen magst mit seinem $\underline{\text { Namen, }}$

daß der Park weint, schwarzgelb wie der Pirol.

$\mathrm{Da}$ die Erde überladen, der Himmel leer ist

(in ihm säuert nur nieselig die Luft),

daß der schreckliche Marmor der römischen Kolonnaden

aus der Erde ragt, als wäre da

eine Kuh verscharrt mit dem Euter nach oben -

im Winter nach Rom zu kommen,

ist wie im Schweigen (Rauschen) des Jungfräulichen Wassers das Herz zu ertränken, wie die Sonne aus Schnee auszugraben ${ }^{27}$.

\footnotetext{
${ }^{26}$ O. Martynova, J. Schwarz, Rom liegt irgendwo..., c. 76-79, шрифт выделен автором статьи - Д. Х.

${ }^{27}$ Там же. Шрифт выделен автором статьи - Д. Х.
} 


\section{Язык птиц и транскультурность}

В книге с русскими стихами под названием $O$ Введенском. $O$ Чвирике и Чвирке. Исследования в стихах (2010), которая связана с книгой о попуга$9 \mathrm{x}^{28}$, ссылка на Введенского есть уже в названии. Книга о Чвирике и Чвирке отсылает нас к Объединению реального искусства, ОБЭРИУ, куда входили, например, Даниил Хармс, Александр Введенский и Николай Заболоцкий. ОБЭРИУты следовали поэтике абсурда. Ева Хаусбахер считает, что стихи Мартыновой основаны на чувственно-вокальном, перемещающемся между смыслом и бессмыслицей ${ }^{29}$. В стихах рассказывается о птицах и других животных, например, в стихотворении ПТИЦА КАГУ.

\section{ПТИЦА КАГУ}

Кагу (Rhinochetus jubatus), птица отряда

журавлеобразных; единственный представитель подотряда кагу. [...]

Распространен в горных лесах острова

Н. Каледония на площади не более 40 км² $^{2}$.

(БСЭ)

Видишь: на разломе лето дождливо, как червив бывает гриб на разломе.

За лучистой шторкой, слышишь, божий Чвирик, чивирикает, а что - и сам не знает.

Распускают свои перья и клювы, да ерошатся в невинном ознобе птица-ромб, и птица-крест, и птица-окружность, и треугольники-птицы обе.

А птица Кагу с островка в окияне, как напудренный вельможа в холе-пьяни.

${ }^{28}$ О взаимосвязи двух книг пишет Виктор Бейлис: «А теперь необходимо вспомнить, что стихи о Чвирике и Чвирке имеют подзаголовок: “стихи из романа о попугаях”. Русские стихи из романа, написанного по-немецки и существующего только на этом языке ("Sogar Papageien überleben uns")! Это, вообще говоря, дерзость неслыханная - на такое не решился даже абсолютно бесстрашный двуязычный Набоков, хотя и подошел к такому замыслу невероятно близко, но все же не ближе мультилингвистических каламбуров. Но стихи и не включены в роман, и роман не о попугаях! Стихи все же принадлежат, вероятно, героине романа, от лица которой ведется повествование». В. Бейлис, Предисловие..., с. 31-32.

${ }^{29}$ E. Hausbacher, Von Tschwirik und Tschwirka. Zum transkulturellen Potenzial von Olga Martynovas Vogelstimmen, [в:] E. Binder, S. Klettenhammer, B. Mertz-Baumgartner, Lyrik transkulturell, Würzburg: Königshausen \& Neumann 2016, c. 291. 
Попугаи, попуга, попу, по, кто их выпустил из рая (и зря)? Перья белые щипали на груди, перья красные ложились в борозду.

и взволнованно шагали птицы-по на разломе швырестела земля, и какие-то «ти-ти» или «ди-ди» божий Чвирик чивирикал в (с)аду.

А птица Кагу, захудалый вельможа, Смотрит, пыльную косицу ероша. В черном сыре понавыела ворона звездных дырок, а сама улетела.

Ворон прядал бы ушами - да нечем, Конь закаркал бы, да не дал бог слуха.

Неумело подпевают чивирику птица-ромб, и птица-крест, и птица-окружность, а треугольники-птицы обе завистливо зависли в небе.

А птица Кагу на островке -

В сапожках красных, в величавом парике ${ }^{30}$.

Хаусбахер напоминает, что птицы всегда были символами поэта, и что язык птиц также имеет транскультурное измерение ${ }^{31}$. Птицы, как она объясняет, присутствовали еще в русском авангарде. Велимир Хлебников предлагал рассматривать птичий язык в качестве универсального и мирового языка, как противопоставление национальным языкам ${ }^{32}$. Подобным образом относится к языку птиц, например, современный транскультурный поэт Йоко Тавада ${ }^{33}$. Ссылки на транскультурный язык птиц поддерживаются еще и межтекстовыми ссылками на различных писателей, которые играют определенную роль в текстах Мартыновой - например, на Гете, Мерике, Гельдерлина и на русских писателей - Хармса, Введенского, Бродского и Цветаеву.

Интертекстуальные ссылки на других авторов, в частности представителей немецкой и русской литератур, а также транскультурные ссылки на Италию, показывают, что тексты Мартыновой не вписываются одноязычно

\footnotetext{
${ }^{30}$ О. Мартынова, О Введенском..., с. 37-38.

${ }^{31}$ E. Hausbacher, Von Tschwirik und Tschwirka..., c. 289.

${ }^{32}$ Там же, с. 291.

${ }^{33}$ Там же, с. 289.
} 
ни в одну литературную традицию. Читатели, независимо от того, на каком языке они читают тексты Мартыновой - на русском, немецком или в переводе - погружаются в ее многоязычный транскультурный мир.

\section{References}

Beilis, Viktor. Predislovie. In: Martynova, Olga. O Vvedenskom. O Chvirike i Chvirke. Issledovaniya v stikhakh. Moskva: Tsentr sovremennoi literatury, 2010.

Brežná, Irena. Die undankbare Fremde. Berlin: Galiani, 2012.

Dabić, Mascha. Reibungsverluste. Wien: Edition Atelier, 2017.

Emerson, Caryl. The Cambridge Introduction to Russian Literature. Cambridge et al.: Cambridge University Press, 2008.

Ginsburg, Mikhal Peled. Portrait Stories. New York: Fordham University Press, 2015.

Gryasnowa, Olga. Der Russe ist einer, der Birken liebt. München: Hanser, 2012.

Haines, Brigid. "Introduction. The Eastern European Turn in Contemporary German-Language Literature". German Life and Letters, No. 68/2 (2015): 145-153.

Hausbacher, Eva. Von Tschwirik und Tschwirka. Zum transkulturellen Potenzial von Olga Martynovas Vogelstimmen. In: Lyrik transkulturell, ed. E. Binder, S. Klettenhammer, B. Mertz-Baumgartner. Würzburg: Königshausen \& Neumann, 2016: 289-310.

Martynova, Olga. Dichter im Porträt. Olga Martynova. https://www.youtube.com/watch?v=hr4H VOuULE\&feature=youtu.be.

Martynova, Olga. O Vvedenskom. O Chvirike i Chvirke. Issledovaniya v stikhach. Moskva: Tsentr sovremennoi literatury, 2010: 9-14.

Martynova, Olga. Sogar Papageien überleben uns. München: btb, 2012 [Graz, Wien: Droschl, 2010].

Martynova, Olga. Von Tschwirik und Tschwirka. Gedichte. Graz, Wien: Droschl, 2012 [=Martynova 2012b].

Martynova, Olga, Schwarz, Jelena. Rom liegt irgendwo in Russland. Zwei russische Dichterinnen im lyrischen Dialog über Rom. Gedichte Russisch / Deutsch, trans. E. Erb, O. Martynova. Wien, Lana: Edition per procura, 2006.

Pearson, Irene. "Raphael as Seen by Russian Writers from Zhukovsky to Turgenev". In: The Slavonic and East European Review, No. 59/3 (1981): 346-369.

Radaelli, Giulia. Literarische Mehrsprachigkeit. Sprachwechsel bei Elias Canetti und Ingeborg Bachmann. Berlin: Akademie Verlag, 2011.

Shishkin, Mikhail. Venerin volos. Moskva: Vagrius, 2005.

Ulitskaya, Lyudmila E. Daniel Stein, perevodchik. Moskva: Eksmo, 2006. 